\title{
Nerve Abscess in Lepromatous Leprosy - Report of a Patient
}

\author{
C. K. JOB, B.sc., M.D., M.C.PATh. \\ Professor of Pathology \\ C. BHAKTAVIZIAM, в.A., м.в.B.s., DV.M.s. \\ Head of the Department of Dermatology \\ Christian Medical College and Hospital, Vellore, South India
}

Nerve abscess is quite well known in the tuberculoid type of leprosy and is analgous to the 'cold abscess' of tuberculosis, but its existence in lepromatous type of leprosy has always been in doubt. Hughes ${ }^{4}$ states that nerve abscess is found only in the tuberculoid type of leprosy. However, Austin ${ }^{1}$ has seen nerve abscess in 2 patients with lepromatous leprosy but failed to make the necessary investigations. The lepromatous patient with nerve abscess which Muir ${ }^{7}$ had recorded belongs to the 'cold abscess' type and the patient is thought to be 'neural' to start with. Wade ${ }^{10}$ in 1939 had mentioned 2 lepromatous leprosy patients with nerve abscesses which differed grossly and histologically from 'the cold abscess' seen in tuberculoid patients. Later, in an editorial in the same journal in 1953 Wade $^{11}$ had asked to report any patient with lepromatous nerve abscess proved histologically. Subsequantly Sato $^{8}$ in 1956 reported a patient with lepromatous leprosy with a cutaneous nerve abscess which histologically showed lepromatous granuloma with abundant bacilli but hardly any polymorphonuclear leucocytes.

In this paper we report a patient with lepromatous leprosy presenting with erythema nodosum leprosum (ENL) and having an acute nerve abscess proved histologically.

C.M.C.H. 399299: A 29-year-old male patient with lepromatous leprosy presented with a complaint of having painful nodules all over the body off and on for 3 years. He was diagnosed as a leprosy patient 3 years ago while having fever and arthritis and was treated with
Diamino Diphenyl Sulphone (DDS). This treatment precipitated an attack of ENL. Since then he had had recurrent attacks of ENL On examination there was diffuse fine infiltration and erythema of the skin of the trunk, face and extremities. Bilateral glove and stocking anaesthesia was present. There was also oedema of the hands and feet. The right ulnar nerve was thickened and painful. Scattered tender nodules were present all over the body. One of these was biopsied.

\section{INVESTIGATIONS}

Skin smears were done according to the Wade's technique ${ }^{9}$ and graded as per Cochrane's method $^{2}$.

$\begin{array}{ll}\text { Ear } & 1 \text { plus } \\ \text { Forehead } & 1 \text { plus } \\ \text { Cheek } & 1 \text { plus } \\ \text { Arm } & 1 \text { plus } \\ \text { Chest } & \text { Only occasional bacilli } \\ \text { Back } & \text { Only occasional bacilli } \\ \text { Buttock } & \text { Only occasional bacilli }\end{array}$

Urine examination showed no abnormality.

\section{HISTOPATHOLOGICAL REPORT}

The biopsy consisted of an elliptical piece of skin measuring $2 \mathrm{~cm}$. long. The tissue was bisected and it revealed a nodule in the subcutaneous tissue measuring $0.4 \mathrm{~cm}$. in diameter. It was fixed in $10 \%$ formalin, processed and several paraffin sections were made. Haematoxylin and Eosin stain, acid fast stain according to the Fite's method $^{3}$, Loyes myelin stain and 


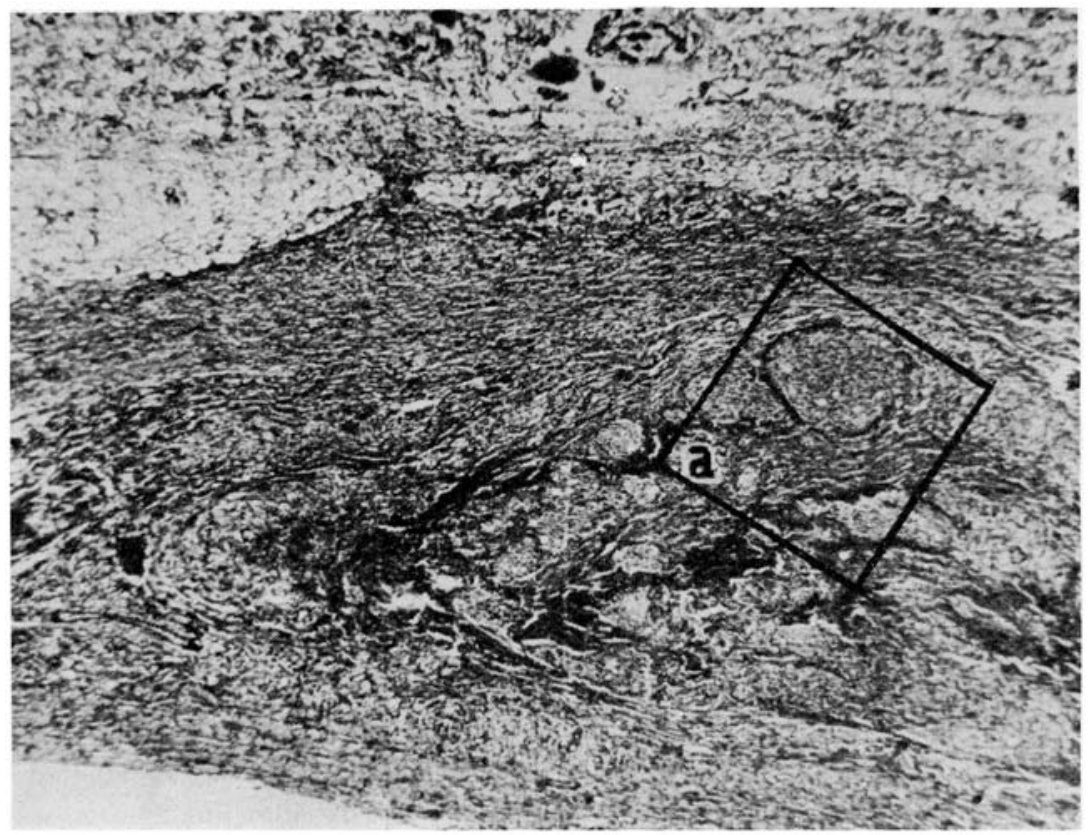

FIG. 1

Photomicropgraph of the subcutaneous nodule to show the abscess involving the nerve.

( $\mathrm{H} \& \mathrm{E} \times 3()$.)

FIG. 2

Field in Fig. I magnified to show a part of the abscess composed almost entirely of polymorphonuclear leucocytes.

(H \& $\mathrm{E} \times 150$.

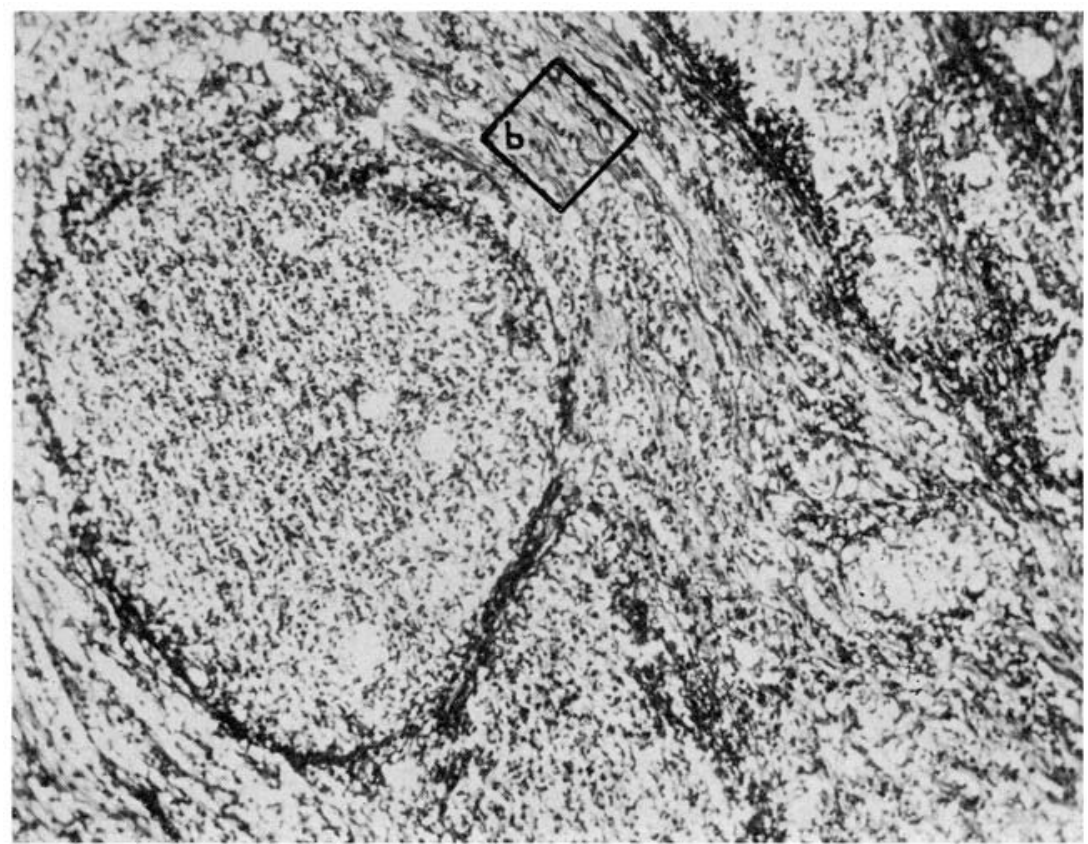




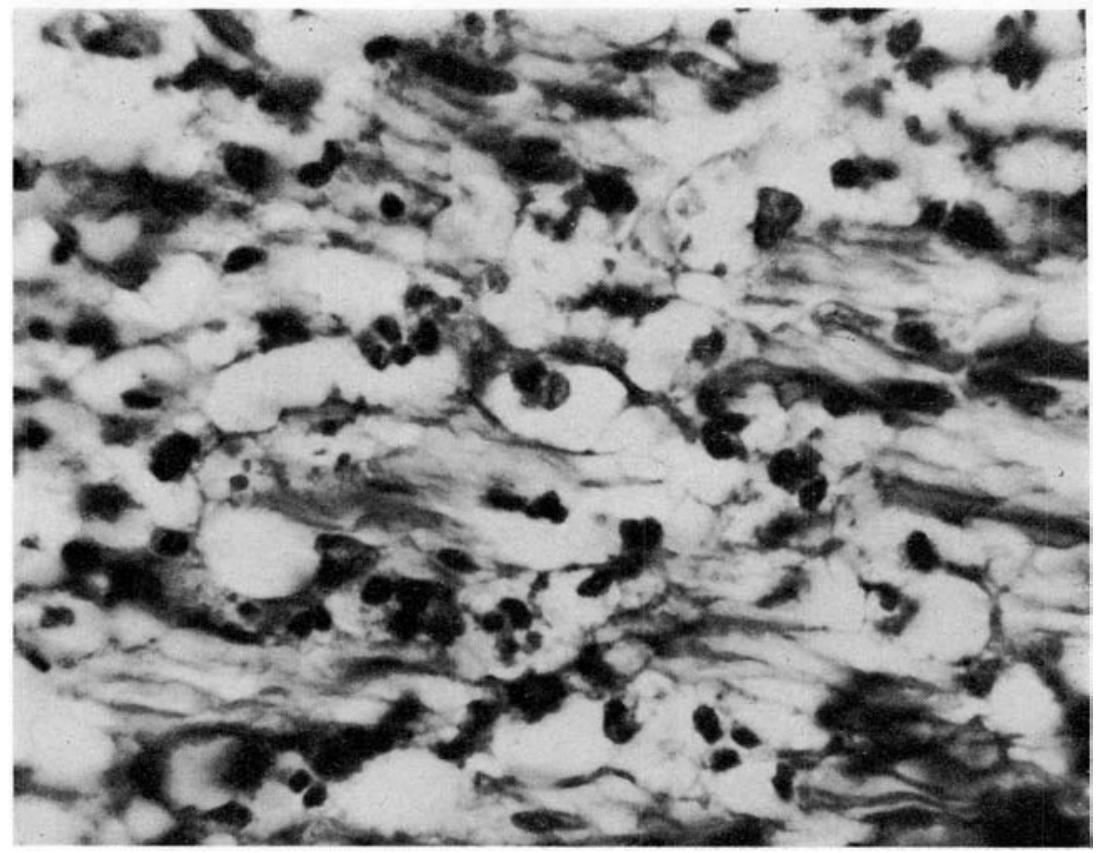

FIG. 3

Field in Fig. 2 magnified to show the nerve bundle infiltrated with numerous polymorphonuclear leucocytes.

$(\mathrm{H} \& \mathrm{E} \times 1100$.)

FIG 4.

Fragmented nerve fibres are seen densely infiltrated with polymorphonuclear leucocytes.

The tissue is oedematous. (Bodian $\times 150$. $)$

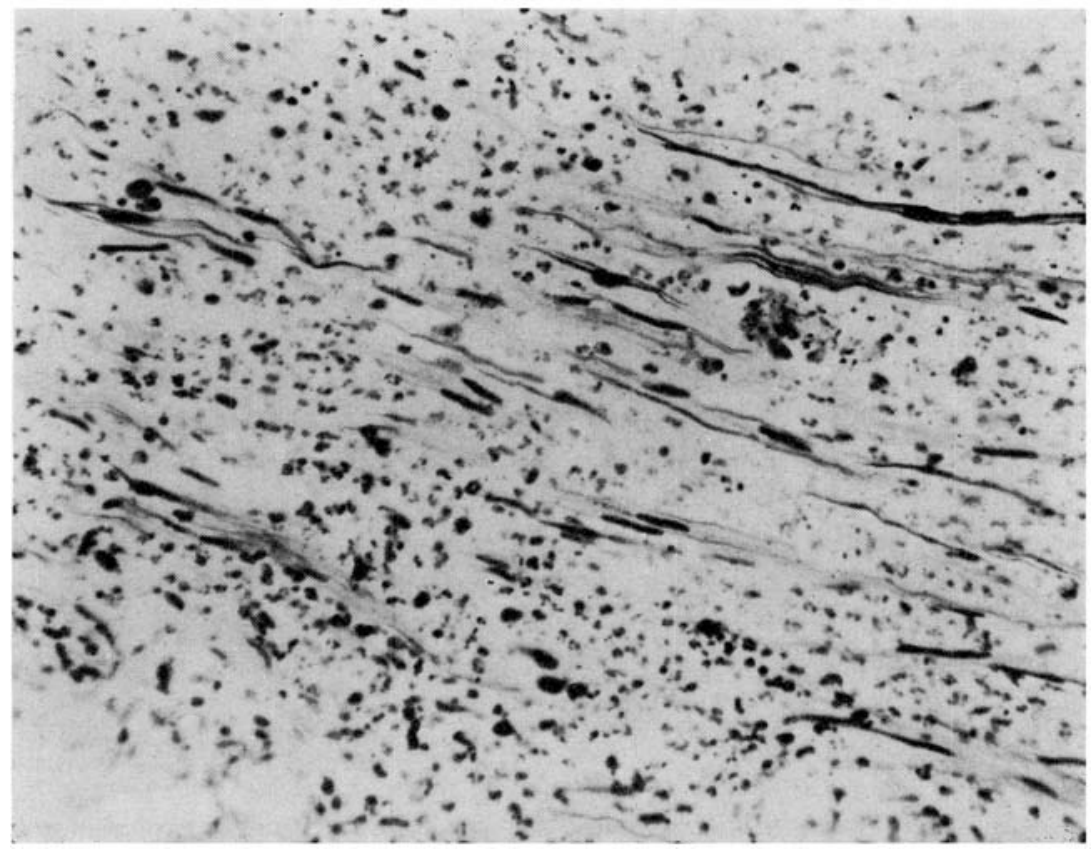

Nerve Abscess in Lepromatous Leprosy-Report of a Patient 245 


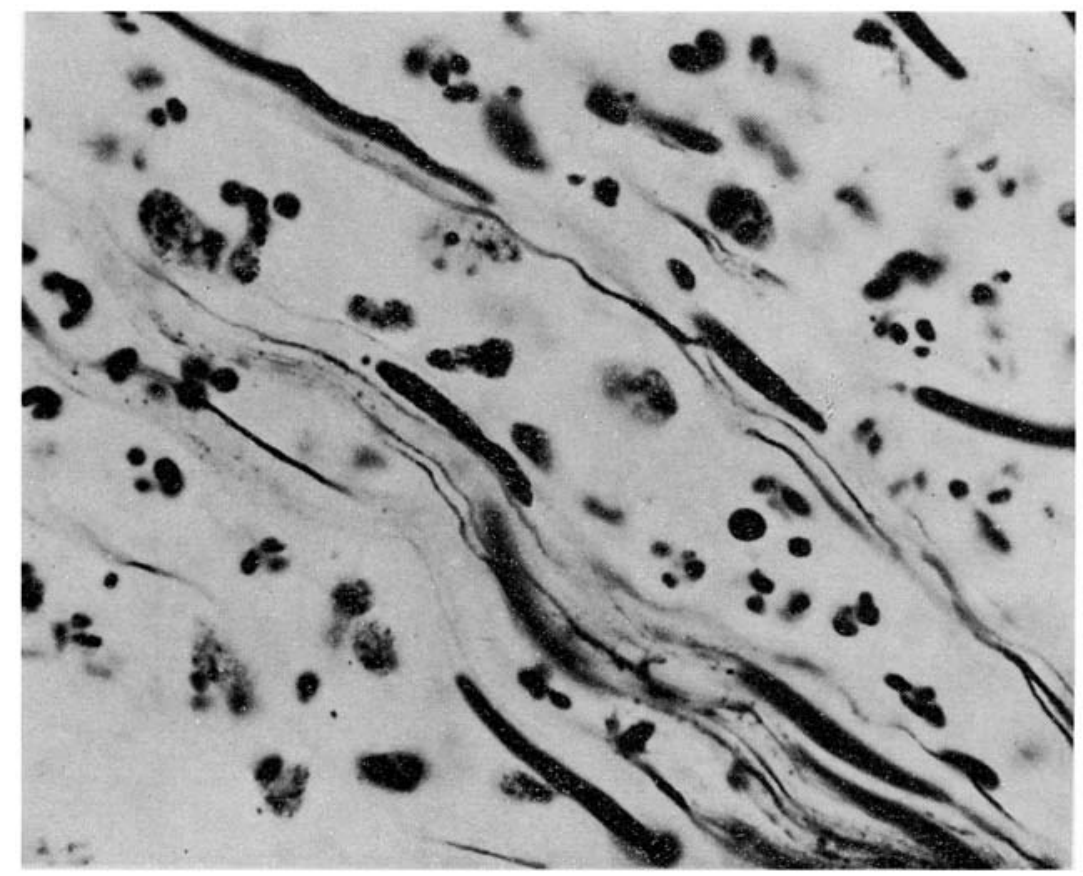

FIG. 5

Higher power

photomicrograph to show clearly the fragmented nerve fibres infiltrated with numerous polymorphs. (Bodian $\times 1100$.

Bodian stain for axis cylinders in paraffin sections were prepared.

Histopathological examination showed epidermis with some proliferation of the prickle cell layer. In the corium were focal collections of inflammatory cells consisting of mainly lymphocytes and plasma cells. They were collected around skin appendages. There was marked increase in vascularity and the blood vessels were also surrounded by the inflammatory cells.

The chief lesion was a nodule in the subcutaneous tissue.

The nodule consisted of a subcutaneously placed nerve showing pronounced oedema and severe inflammation. Large collections of foamy macrophages with markedly vacuolated cytoplasm had infiltrated the nerve separating widely the nerve fibres. The nerve was also diffusely infiltrated with numerous neutrophilic polymorphonuclear leucocytes which in areas were densely packed together to form abscesses.

There was endothelial proliferation with formation of new capillaries. In the myelin stain total demyelination of the nerve fibres was seen. The Bodian preparation showed much fragmentation and destruction of nerve fibres. A few fragmented remanants of the axons were made out.

Numerous acid fast bacilli were present inside Schwann cells. Most of them were broken and granular. The macrophages did not show any bacilli.

\section{COMMENTS}

This patient with lepromatous leprosy presents all the features of lepromatous nerve abscess the histopathological appearance of which has been predicted by several others earlier. Muir ${ }^{3}$ had suggested that the nerve abscess in lepromatous leprosy should be like the skin nodule in 'lepra reaction' containing pus filled with leucocytes and a large number of acid fast bacilli. Wade ${ }^{7}$ suggested that the nerve abscess in the cutaneous type (lepromatous type) is an acute condition and admittedly due to a lepra reaction phenomenon'. In this patient the nerve abscess occurred during an attack of 
erythema nodosum leprosum and the nerve was densely packed with neutrophilic polymorphonuclear leucocytes forming an abscess. Acid fast stain showed numerous acid fast bacilli.

Erythema nodosum leprosum is thought to be a hypersensitivity reaction. The exact pathogenesis of the phenomenon is not well understood. In our experience most of the ENL lesions occur in an already existing granuloma of macrophages containing acid fast bacilli which are mostly broken and granulated. ${ }^{5}$ The well known site of ENL is the skin. However, one of the authors has seen ENL-like reaction in the lymph nodes which are extensively replaced by lepromatous granulation tissue ${ }^{6}$.

The nerve seen in the patient under report showed a lepromatous granuloma together with an abscess composed of polymorphonuclear leucocytes. Numerous broken and granular bacilli were also present in the Schwann cells. This nerve lesion is present in association with numerous other skin nodules typical of ENL. Therefore, it proves beyond doubt for the first time that ENL-like reaction with abscess formation takes place in the nerve tissue also.

\section{SUMMARY}

An acute subcutaenous nerve abscess in a patient with lepromatous leprosy is presented.
Histopathological appearance of the nerve abscess is typical of the ENL with lepromatous granuloma infiltrated with large collection of polymorphonuclear leucocytes.

\section{ACKNOWLEDGEMENTS}

We acknowledge with thanks the technical help received from Mr. R. Shanthakumar and Mr. S. Jesudoss and the secretarial help from Mr. K. George William.

\section{REFERENCES}

1. Austin, c. J. Int. .J. Lepr. (1939), 7, 274. (Correspondence.)

2. Cochrane, R. G. A Practical Text Book of Leprosy, 1947 edition, $70-71$.

3. Fite, G. L., CAMBRe, F. J. and TURNER, M. H. Arch. Path. (1947), 43, 624-625.

4. hughes, w. Trans. Roy. Soc. Trop. Med. \& Hyg. (1937-1938), 31, 383-399.

5. Jов, С. K., GUdE, s. and MACADEN, v. P. Int. .J. Lepr. (1964), 32, $177-184$.

6. Јов, С. K. and KARAT, A. B. A. Unpublished observations.

7. MUIR, E. Int. J. Lepr. (1939), 7, 274. (Correspondence.)

8. SAтo, s. Int. .J. Lepr. (1956), 24, 408-418.

9. Wade, H. W. Lep. Rev. (1935), 6, 54.

10. WADE, H. W. Int. J. Lepr. (1939), 7, 274.

11. WAde, H. w. Int. J. Lepr. (1955), 23, 69-71. (Editorial.) 